\title{
Um movimento católico na política: 0 caso do Comunhão e Libertação
}

A Catholic Movement in Politics: The Case of Communion and Liberation

Un mouvement catholique dans la politique : le cas du mouvement Communion

et Libération

Alberta Giorgi e Emanuele Polizzi

Tradutor: Teresa Tavares

\section{OpenEdition}

\section{Journals}

Edição electrónica

URL: http://journals.openedition.org/rccs/4912

DOI: $10.4000 /$ rccs. 4912

ISSN: 2182-7435

\section{Editora}

Centro de Estudos Sociais da Universidade de Coimbra

\section{Edição impressa}

Data de publição: 1 Junho 2012

Paginação: 41-60

ISSN: 0254-1106

Refêrencia eletrónica

Alberta Giorgi e Emanuele Polizzi, « Um movimento católico na política: O caso do Comunhão e Libertação », Revista Crítica de Ciências Sociais [Online], 97 | 2012, colocado online no dia 19 abril 2013, criado a 01 maio 2019. URL : http://journals.openedition.org/rccs/4912 ; DOI : 10.4000/rccs.4912 


\section{ALBERTA GIORGI EMANUELE POLIZZI}

\section{Um movimento católico na política: O caso do Comunhão e Libertação}

Comunhão e Liberação (CL) é amplamente reconhecido em Itália como um importante movimento católico, cujo poder político tem crescido de forma significativa nos últimos 15 anos. Caracterizado por uma forte identidade que conjuga tradição e modernidade, o CL tem conseguido ampliar o número dos seus aderentes e a sua presença a nível social, económico e político. Trata-se, portanto, de um exemplo bem-sucedido de movimento religioso no cenário político contemporâneo.

Este artigo aborda a relação entre o CL e o contexto político italiano no período da Segunda República (de 1993 até aos nossos dias), através da análise, por um lado, da representação que o $C L$ faz do seu próprio papel político, e, por outro, da estrutura de oportunidades políticas que possibilitou o seu sucesso.

Palavras-chave: Itália; movimento católico Comunhão e Libertação (CL); movimentos religiosos; poder político e religião; política; religião; estrutura de oportunidades políticas.

\section{Introdução: objetivos e âmbito}

Comunhão e Libertação (CL) é um conhecido movimento católico cujo poder político tem aumentado significativamente nos últimos quinze anos. Apesar disto, poucos estudos sociológicos se têm debruçado sobre as razões do seu êxito.

Podemos distinguir duas principais correntes de análise do movimento a nível nacional e internacional. A primeira inclui maioritariamente estudos críticos de investigadores italianos, levados a cabo entre o final da década de 1960 e o início da década de 1980 (Bianchi e Turchini, 1975; Cavallaro, 1976; Centro Operaio, 1975; Ottaviano, 1986; Saraceno e Rusconi, 1970), que se concentraram no caráter político do CL, frequentemente rotulado como grupo integrista. A investigação, maioritariamente dominada por uma abordagem marxista, incidiu na história do movimento, nos perfis socioeconómicos dos seus membros, na sua estrutura organizativa, ideologia e visão política. Embora esta primeira corrente tenha feito uma análise 
detalhada do CL, especialmente da sua dimensão política, não pôde necessariamente tomar em conta as grandes transformações ocorridas no cenário político italiano após a década de 1990, na sequência do fim da Primeira República (1948-1994) e da dissolução do partido dominante, o Partido da Democracia Cristã.

A segunda corrente de análise, tanto a nível nacional como internacional, aborda o CL principalmente como movimento religioso, analisando a sua organização interna e as suas causas (Abbruzzese, 2001 e 1991; Almond, Appleby e Sivan, 2006; Bova, 2005; Gervasi, 2007; Guolo e Pace, 1998; Marzano, 1997 e 1995; Pace, 1998; Zadra, 1994). ${ }^{2}$ A maioria destes estudos define o CL como grupo fundamentalista. No entanto, parece-nos que as categorias de integrismo e fundamentalismo nada nos dizem acerca dos complexos mecanismos de interação entre religião e política protagonizados pelo CL. Concretamente, o movimento tem tido grande sucesso em articular a sua natureza local e comunitária com a capacidade de fazer política a nível nacional. Por conseguinte, temos de tomar em consideração essa capacidade de intervenção política em diferentes planos territoriais, enquadrando a relação entre o CL e o sistema político numa perspetiva de governação de múltiplos níveis, não incidindo apenas no nível nacional ou local, como o fizeram as análises anteriores. Assim, embora baseado num só movimento, este estudo apresenta contributos relevantes para a análise das relações contemporâneas entre a religião e a política.

O propósito deste artigo é articular a análise dos discursos do CL com a sua estrutura de oportunidades políticas, incidindo especificamente na conceção do seu papel político e no modo como a transformação do cenário político italiano poderá ter influenciado as relações entre este movimento e a esfera política.

$\mathrm{Na}$ primeira secção do artigo, debruçamo-nos sobre a história do CL como movimento; na segunda, analisamos a política do CL; na terceira, abordamos a estrutura favorável de oportunidades políticas que influenciou o seu desenvolvimento e crescimento; e finalmente, na quarta secção, apresentamos algumas conclusões.

\footnotetext{
${ }_{1}^{1}$ Após a Segunda Guerra Mundial, o referendo constitucional de 2 de junho de 1946 deu a vitória aos republicanos e aboliu a monarquia. A nova constituição, elaborada pela Assembleia Constituinte, entrou em vigor a 1 de janeiro de 1948, e as eleições de 18 de abril de 1948 assinalaram o nascimento político da primeira república italiana (Galli, 1984).

2 Para além dos estudos das duas correntes mencionadas, encontramos ainda publicações do próprio CL (Camisasca, 2001, 2003, 2006; Ronza, 1976) e de autores ligados à Igreja (cf. Favale, 1991), bem como peças de jornalismo investigativo (e.g. De Alessandri, 2010; Pinotti, 2010).
} 


\section{A história do $\mathrm{CL}$}

\subsection{Origens}

A história do CL teve início em 1954, nas salas de aula de um liceu do centro de Milão, quando um jovem padre, Luigi Giussani, decidiu abandonar a docência de Teologia para ensinar religião em escolas públicas. Ele tinha-se apercebido de que, apesar de a Itália ser historicamente um país católico, a religião cristã era praticamente irrelevante na vida dos jovens. Para além disto, o socialismo e o liberalismo, os movimentos culturais e políticos dominantes da modernidade, eram essencialmente ateístas e contrários à presença da religião na esfera pública (Bianchi e Turchini, 1975; Camisasca, 2001; Abbruzzese, 1991).

Os ensinamentos de Giussani visavam desafiar os/as estudantes através de uma abordagem provocadora. Apresentava a "vida cristã" como uma proposta revolucionária que não deixava as pessoas indiferentes, apelando a que os/as jovens repensassem e reconstruíssem todos os aspetos das suas vidas, incluindo as atividades sociais e políticas, como forma de afirmar a sua identidade cristã. Esta posição constituía uma reação à distinção entre o religioso e o secular, proposta nessa altura por muitos filósofos e teólogos católicos (como Jacques Maritain), que acabou por se tornar numa espécie de dualismo fraturante entre a fé e a vida social (Camisasca, 2001; Formigoni e Vecchio, 1989). Em pouco tempo, a nova abordagem e a popularidade de Giussani difundiram-se por toda a cidade de Milão. O seu êxito deveu-se não só ao caráter inovador da sua proposta, mas também ao seu papel na Azione Cattolica (AC), a maior organização católica em Itália, particularmente na Gioventù Studentesca (GS), a secção local da AC para estudantes do ensino secundário, onde desempenhava a função de conselheiro espiritual. No início da década de 1960, o nome da GS passou a estar intimamente associado a Giussani, e essa ligação permitiu-lhe alargar o seu público, tornando-se o líder do maior grupo de estudantes católicos, tanto em Milão como noutras cidades da Lombardia. Sob a sua direção, os membros do GS tinham uma experiência intensa de vida em comunidade, que incluía várias atividades: orações diárias, encontros espirituais sobre a fé e a vida quotidiana e ações de solidariedade, nomeadamente junto das crianças pobres dos subúrbios de Milão, ensinando-as a seguir os princípios da fé católica (Camisasca, 2001).

Para compreender o êxito popular da GS é também relevante tomar em conta o contexto católico em que esta experiência se desenrolou. $\mathrm{Na}$ sequência da Segunda Guerra Mundial, a Igreja Católica italiana, sob o Papa Pio XII, empenhou-se profundamente no combate ao comunismo, tanto no domínio político como cultural. A AC mobilizou-se intensamente 
para esta causa e organizaram-se grupos cívicos para impedir a influência das poderosas organizações comunistas sobre a classe trabalhadora (Guasco, 1997; Riccardi, 2007). Animado pela premência deste propósito, o movimento leigo manifestou um empenhamento político profundo e alargado, que, no entanto, levou ao enfraquecimento da dimensão espiritual das suas atividades - e os estudantes do ensino secundário, demasiadamente jovens para se envolverem nas eleições, foram praticamente negligenciados pela AC. Por contraste, a proposta de Giussani dirigia-se diretamente aos jovens e apresentava várias características que a tornavam atrativa para a juventude: eliminava a tradicional divisão sexual das organizações religiosas, usava a linguagem das emoções e propunha uma fé militante.

O crescimento deste novo movimento, no entanto, ameaçava desencadear fenómenos de concorrência entre o CL e as estruturas estabelecidas da Igreja. Em 1965, o Arcebispo de Milão, Cardeal Colombo, determinou que Giussani abandonasse as suas funções de responsável direto do movimento e que a GS passasse a integrar a AC. Ao mesmo tempo, nomeou Angelo Scola, um dos discípulos mais importantes de Giussani (atualmente Arcebispo de Milão), para o cargo de presidente da Federazione Universitaria Cattolica Italiana (FUCI), a secção universitária da AC.

Nos anos seguintes, a revolução de maio de 1968 espalhou-se por todas as universidades italianas, tal como aconteceu em muitos países ocidentais. A GS e o movimento estudantil partilhavam vários ideais e valores fundamentais: o antiautoritarismo, o anticapitalismo, a crítica ao "conformismo cultural" e à hipocrisia da separação entre esfera pública e privada. Contudo, Giussani encarou 1968 como uma ameaça ao seu movimento, o qual, na sua perspetiva, deveria continuar a concentrar-se em objetivos religiosos e educativos: a resposta às necessidades das pessoas residia na pertença a uma comunidade de fé e não no comprometimento político (ver Saraceno e Rusconi, 1970). As diferenças e semelhanças entre a GS e o movimento estudantil de 1968 causaram fortes tensões dentro da GS e muitos dos seus membros decidiram abandoná-la para se juntarem ao movimento estudantil. No final de 1968, apenas uma minoria se mantinha filiada na organização de Giussani.

O movimento estudantil de 1968 constituiu, portanto, uma viragem na história da GS. De regresso à direção, Giussani tentou definir mais claramente a identidade do movimento. Como reação aos problemas e ambiguidades do período anterior, concentrou-se no seu caráter religioso, pelo que as atividades políticas, embora não fossem negligenciadas, eram consideradas unicamente como um meio de defender princípios religiosos. Pode dizer-se que este foi um momento de refundação do movimento, 
e mesmo o seu nome se alterou para Comunhão e Libertação, sublinhando deste modo o começo de uma nova história (Camisasca, 2001 e 2004; Ottaviano, 1986).

Este novo início teve importantes consequências para o desenvolvimento do movimento. A posição cultural do CL tornou-se cada vez mais reativa às posições dos grupos de esquerda que surgiram do movimento estudantil de 1968 em Itália, e a primazia da religião sobre a política tornou-se mais explícita. Neste período, desenvolveram-se três tipos de atividades: 1) provisão de serviços para responder às necessidades dos estudantes, como livrarias e cantinas, bem como às das famílias, como escolas, apoio social a crianças, alojamento, apoio na procura de emprego; 2) promoção da identidade e valores do CL através da publicação de revistas, da realização de congressos e da criação de uma editora; 3) entrada na arena política para eleger representantes seus em instituições políticas, como o fim de facilitar as atividades económicas do CL e ao mesmo tempo divulgar as suas campanhas culturais.

\subsection{A chegada ao poder}

Em 1975, o CL criou uma nova organização para coordenar a sua ação política - o Movimento Popular (MP). Sob este nome, o CL passou a integrar o partido dominante na época, o Partido da Democracia Cristã (DC), e conseguiu eleger alguns dos seus membros para as câmaras municipais, as assembleias regionais e mesmo os parlamentos italiano e europeu. Muitos dos seus representantes tornaram-se importantes dirigentes do DC e conseguiram alcançar posições de destaque no governo local durante a década de 1980 (Camisasca, 2003). Em 1992-93, com a desagregação do DC em consequência dos escândalos de corrupção em que estiveram envolvidos membros do MP, o CL decidiu afastar-se da política temporariamente, dissolvendo o MP e esperando para ver os desenvolvimentos que ocorreriam no sistema político italiano na sequência da crise.

No final da década de 1980, foi também criada uma outra organização dentro do CL para coordenar as suas atividades económicas - a Compagnia delle Opere (conhecida informalmente como CdO). Esta organização adquiriu vasta importância dentro do movimento, nomeadamente a partir de 1987, quando Giussani apontou para a subsidiariedade horizontal - a organização concreta de ações locais para apoiar atividades económicas e sociais - como o caminho para o envolvimento político. Depois da dissolução do MP, a $\mathrm{CdO}$ passou a ser vista como sua herdeira.

Quando em 1995 se encontrou um novo equilíbrio bipolar na política italiana, a maioria dos membros do CL decidiu apoiar a coligação de 
centro-direita liderada por Silvio Berlusconi, dando assim início a uma nova estratégia política de âmbito nacional. Em 1997, Roberto Formigoni, antigo presidente do MP, aderiu ao partido de Berlusconi, Forza Italia, fundando uma das suas correntes mais poderosas (conhecida atualmente como "Rete Italia”). Para além desta estratégia a nível nacional, nas zonas locais em que o centro-direita tinha pouca expressão, o CL chegou mesmo a apoiar alguns dirigentes do centro-esquerda (Pinotti, 2010).

A partir daí o CL concentrou as suas energias políticas no nível regional, dado que as reformas institucionais da década de 1990 transferiram muitos recursos e poderes para as regiões. Em 1995, o CL conseguiu apresentar Formigoni como candidato a presidente da Lombardia - a região mais rica e populosa da Itália, onde o movimento goza de maior poder -, tendo este ganho as eleições contra a coligação de centro-esquerda. Esta vitória permitiu ao CL colocar os seus membros em toda a imensa máquina burocrática da administração regional e proporcionar muitos recursos às suas organizações com e sem fins lucrativos através da reforma das políticas públicas de subsidiarização. O movimento conseguiu estabelecer uma eficaz estratégia de consenso que possibilitou a reeleição de Formigoni em quatro mandatos, atingindo assim o recorde como o presidente regional de maior longevidade na história da Itália. Ao mesmo tempo, durante as décadas de 1980 e 1990, as atividades económicas do CL cresceram e a CdO tornou-se no maior consórcio económico da Lombardia.

Hoje em dia o CL é amplamente reconhecido como líder da política lombarda e um dos grupos mais poderosos do partido de Berlusconi. Até há pouco tempo, as expectativas apontavam para Formigoni como um dos sucessores mais prováveis de Berlusconi na direção da coligação de centro-direita.

\subsection{A autodefinição do $\mathrm{CL}$}

Desde o início que a autodefinição do CL se centra na missão educativa e no apoio à juventude (Bianchi e Turchini, 1975; Centro Operaio, 1975; Saraceno e Rusconi, 1970). A participação no movimento implica, primeiro que tudo, frequentar a catequese semanal da "Escola da Comunidade". Embora o foco continue a ser o mesmo, ao longo dos anos alargaram-se os objetivos e significados da missão educativa, que passou a incluir tanto adultos como jovens.

Como sinal desse alargamento, na década de 1980, o movimento começou a organizar grandes eventos públicos para a sociedade em geral. O mais importante é o encontro anual em Rimini no final do verão, com debates coletivos em que são convidadas a discursar as figuras públicas e políticas mais destacadas do país. 
A própria identidade do CL está claramente centrada no seu "método pedagógico", que convida as pessoas a redescobrir a fé como um acontecimento. A força do movimento, tal como emerge das palavras dos seus membros, reside na capacidade de tornar a religião numa força viva e usar a fé como um desafio e um estímulo para enfrentar a realidade. Neste sentido, podemos definir o CL como um movimento católico carismático (Guolo e Pace, 1998; Marzano, 1997), com uma identidade forte e que conta com a dedicação dos seus aderentes, com um líder carismático e uma atitude reativa perante o processo de secularização. $\mathrm{Na}$ sua ótica, a religião tem de ser vivida quotidianamente: uma vez que Deus incarnou, a única forma de $\mathrm{O}$ alcançar é através do humano. Portanto, ser religioso significa viver plenamente no seu tempo e na sua sociedade, e a religião não se reduz a uma lista de valores: "O Jesus dos intelectuais, reduzido a profeta de um socialismo utópico nunca alcançado ou a uma espécie de dispensador de óbvia bondade, é inútil. Pode servir para debates, para polémicas jornalísticas ou para estimular o desejo humano de identificação com um mito ou um herói”. ${ }^{3}$ O CL privilegia, portanto, um saber anti-intelectual, derivado da experiência direta.

Desde o começo que o CL insiste na ideia de que se deve viver a fé quotidianamente e não apenas em momentos e lugares específicos (como na missa dominical). Com este fim, criou "comunidades ambientais" compostas por grupos de pessoas que trabalham ou estudam nos mesmos sítios ou que vivem nos mesmos bairros, superando assim diferenças de estatuto e idade. O movimento não se confina a um local particular, permeando todos os aspetos da vida dos crentes. A proposta de uma fé revolucionária implica o compromisso total dos seus aderentes, e embora não haja uma filiação formal e explícita, esse compromisso estende-se a todos os aspetos da experiência de vida de cada um, pelo que parece ser muito difícil abandonar o movimento, especialmente os seus círculos internos (cf. Marzano, 1997).

Uma vez que a religião se concretiza em obras, as pessoas religiosas têm a missão de educar pelo exemplo e ajudar os outros através de atos. Entre as organizações associadas ao CL, uma das mais importantes é a já mencionada Compagnia delle Opere (CdO), fundada em 1986, uma rede que liga milhares de pequenas e médias empresas, organizações assistenciais, associações culturais e organizações sem fins lucrativos, com o fim de tornar real a presença da religião mesmo no campo económico.

No que diz respeito à relação com a Igreja Católica, o CL sublinha as diferenças entre movimentos e instituições. Enquanto a Igreja tem a

\footnotetext{
${ }^{3}$ Editorial, "A che cosa serve Gesù?", Tracce - Rivista Internazionale de Comunione e Liberazione, maio de 2007. Consultado em http://www.tracce.it/?id=340\&id_n=7853.
} 
função de defender a tradição católica, a tarefa dos movimentos eclesiais é dar vida e concretude tanto à fé como à missão evangélica. Neste sentido, os movimentos não concorrem com a Igreja, mas trabalham antes em articulação com o clero para apoiar a sua presença nas sociedades contemporâneas. O CL parece partilhar com outros movimentos religiosos a ideia de que é o povo eleito, a vanguarda do reino de Deus (cf. Almond, Appleby e Sivan, 2006). Nas palavras de Giussani, "O Senhor iluminou o seu povo [...]. Mais, iluminou os seus eleitos [...]: eu penso sempre que nós estamos entre esses eleitos. Que o Senhor ilumine esta gente sem a qual eu não sou eu!" 4

\section{A conceção de política do $C L$}

2.1. O envolvimento político como parte do compromisso religioso: o papel da religião na sociedade

Embora o CL defenda uma fé revolucionária, não é a favor de mudanças dramáticas. Pelo contrário, as mudanças devem ser graduais, efetuadas através de ações e do exemplo - em suma, através da educação. Com base nesta conceção de mudança, a religião desempenha um papel crucial nas sociedades contemporâneas: a igreja e os movimentos religiosos têm de assumir o seu lugar na esfera pública e envolver-se em todas as áreas da sociedade. O CL critica a ideia da separação entre a religião e a política porque a religião deve ser a razão para todas as ações e opiniões. Nesta perspetiva, a sua posição no debate sobre o secularismo político é a de que a religião deve ter uma forte presença na política: ao sublinhar as origens cristãs do secularismo político, o CL mantém que a Igreja e o Estado têm diferentes funções, sendo que o Estado tem o dever de garantir a presença da religião na esfera pública. Mais, a religião tem não só o direito como o dever de participar na esfera pública, e esse dever é parte da sua identidade. Esta conceção da política é claramente expressa no website do CL:

Numa experiência cristã comprometida, a dimensão política deriva naturalmente da dimensão cultural. Na conceção do CL, a ação política é um dos campos em que um cristão é chamado com grande responsabilidade e generosidade ideal a testar o critério unificador que guia a sua existência em face dos problemas colocados pela vida da sociedade e pelas instituições. [...] A ação política típica da pessoa educada no Movimento deve tender, assim, a criar condições para que o indivíduo e a sociedade, no conjunto das suas atividades de produção, cultura e associação, não sejam

\footnotetext{
${ }^{4}$ Luigi Giussani, "Cristo risorto, la sconfitta del nulla”, Tracce - Rivista Internazionale de Comunione e Liberazione, abril de 2006. Consultado em http://www.tracce.it/?id=339\&id_n=7279.
} 
diminuídos ou penalizados por uma visão estatista ou por uma posição de privilégio concedida apenas a alguns por razões de poder. ${ }^{5}$

A afirmação "mais sociedade, menos Estado" exprime sucintamente a ideia que o CL tem do bem comum, e as palavras-chave do seu sentido de compromisso político são educação, solidariedade e subsidiariedade. $\mathrm{Na}$ verdade, considera-se que se deve ao CL a crescente importância da subsidiariedade no debate político em Itália. ${ }^{6}$ Este princípio é visto como uma forma de gerir a coisa pública com vista ao bem comum, sendo este último a garantia da liberdade individual. A subsidiariedade constitui, assim, uma forma "modernizada" da solidariedade como "terceira via" entre o capitalismo e a economia centralizada. Neste sentido, é vista como um meio de proteger os indivíduos e as iniciativas sociais tanto do Estado como do mercado.

Em resposta às afirmações de que o CL é um movimento político e que, como tal, deseja conquistar o poder, o antigo presidente do $\mathrm{CdO}$ Giorgio Vittadini sublinha que "o nosso papel é e será sempre o de um movimento que educa para um desígnio, que constrói obras e questiona os conteúdos da política, e nunca será o de uma corrente política ou de um partido político". ${ }^{7}$

Relativamente às opções de apoio a partidos políticos, o CL afirma que apoia "os amigos que partilham as nossas posições. Entre as duas formações políticas, [...], não há dúvida de que o centro-direita tem estado mais empenhado nestas lutas [subsidiariedade, liberdade de ensino]". ${ }^{8}$ De facto, a nível nacional, o CL tem apoiado fortemente os partidos de direita, embora tenha também cooperado com políticos de esquerda, especialmente a nível local. Neste sentido, como tem sido frequentemente afirmado, o CL é um movimento pragmático, interessado em criar condições para alcançar os seus próprios objetivos qualquer que seja a situação política.

Contudo, muitos dos seus membros têm-se envolvido diretamente na política e alguns têm sido eleitos para órgãos de governo locais, regionais, nacionais e internacionais. Apesar da afirmação de que estão dispostos a

\footnotetext{
${ }_{5}$ Communion and Liberation - Official International Site: http://www.clonline.org/storiatext/eng/ comlibe/tredimen.htm.

${ }^{6}$ O princípio da subsidiariedade foi introduzido em 2001 na constituição italiana através de votação parlamentar e confirmado por referendo.

7 Giampaolo Cerri, "La politica: per chi, per che cosa", Tracce - Rivista Internazionale de Comunione e Liberazione, setembro de 2000. Consultado em http://www.tracce.it/default. asp?id=266\&id2=190\&id_n=5223.

${ }^{8}$ Giorgio Vittadini, "Opere in rete", Tracce - Rivista Internazionale de Comunione e Liberazione, janeiro de 2000. Consultado em http://www.tracce.it/default.asp?id=266\&id2=183\&id_n=5052.
} 
apoiar quem esteja próximo das suas causas, o facto é que os membros do CL se têm envolvido quase exclusivamente com o PDL (Il Popolo della Libertà), o partido de Berlusconi.

Numa longa entrevista, Formigoni é claro acerca das suas escolhas políticas. Na altura em que foi entrevistado, o PDL ainda não existia e a coligação de centro-direita (Polo) era constituída pela Forza Italia e a Alleanza Nazionale.

(Q) Aderiu à Forza Italia há um ano e meio e houve pessoas, especialmente no mundo católico, que torceram o nariz. Quais as razões que podem ou devem levar um católico a envolver-se com o partido de Berlusconi?

(A) Porque a Forza Italia aderiu ao Partido Popular Europeu [...]. E é um partido em que um católico como eu encontra outros católicos, mas também liberais e reformistas laicos, com quem pode combater na mesma batalha, defendendo os princípios em que sempre acreditei. ${ }^{9}$

O CL revela uma preocupação particular em justificar alianças com base em ideias comuns e como meio de alcançar objetivos políticos. Em especial, a aliança com Berlusconi colocou-lhe alguns problemas, embora o CL tenha sempre conseguido retirar benefícios das derrotas da Forza Italia (e mais tarde do PDL). Por exemplo, quando a coligação de centro-esquerda ganhou as eleições regionais de 2005, exceto na Lombardia e no Veneto, o CL salientou o papel de Formigoni (e portanto do próprio movimento) na "salvação" da Lombardia. Ao mesmo tempo, as palavras de Vittadini exprimiram uma crítica à "demagogia do protagonista solitário". ${ }^{10}$ Apesar de tudo, o CL sempre apoiou os seus aliados, e mesmo no caso dos escândalos sexuais de Berlusconi salientou a necessidade de se avaliar um governo com base nos seus resultados e não na sua moral.

\section{As razões contextuais do êxito do $\mathrm{CL}$}

Para se compreender o êxito político do CL tem de se olhar para a forma como a visão cultural e as características organizativas do movimento se têm articulado com o cenário político italiano dos últimos trinta anos.

\footnotetext{
${ }_{9}$ Rodolfo Casadei, "La navigazione di Roberto", Tracce - Rivista Internazionale de Comunione e Liberazione, março de 2000. Consultado em http://www.tracce.it/default. asp? $\mathrm{id}=266 \& \mathrm{id} 2=185 \& \mathrm{id} \_\mathrm{n}=5088$.

${ }_{10}$ Gianluigi Da Rold, "Elezioni. Per l'Italia un futuro argentino?”, Tracce - Rivista Internazionale de Comunione e Liberazione, abril de 2005. Consultado em http://www.tracce.it/default. asp?id=266\&id2=241\&id_n=6856.
} 
A abordagem proporcionada pela estrutura de oportunidades políticas (Tilly e Tarrow, 2007) fornece-nos um quadro adequado para estudar a forma como as mudanças no panorama político italiano e europeu têm afetado as relações entre o CL e a política.

\subsection{A localização e subsidiarização das políticas}

Uma das razões mais importantes para o sucesso da ação política do CL reside na interação positiva entre a atenção dada pelos seus membros à esfera local e a tendência geral para a localização e subsidiarização das políticas públicas (Brenner, 2004; Ferrera, 2005; Kazepov, 2010).

Desde a década de 1980, muitos países europeus têm levado a cabo um processo de redimensionamento para o nível local das políticas públicas em muitos domínios, como a assistência social, a saúde, a educação, o desenvolvimento industrial e o ambiente. Para além de ter transferido recursos para a administração local, este processo aumentou o poder das elites políticas locais, pelo que ser eleito presidente de câmara municipal ou de governo regional passou a significar ter controlo sobre uma maior fatia do orçamento público e sobre um maior número de cargos administrativos importantes, bem como deter uma posição de forte prestígio em termos de exposição mediática e política.

Ao mesmo tempo, a subsidiarização das políticas públicas, e particularmente a externalização dos serviços de assistência social, deslocou uma imensa parte dos fundos públicos para organizações públicas e privadas, com ou sem fins lucrativos, desencadeando muitas vezes fenómenos de concorrência por recursos (como acontece em vários sistemas de saúde - ver, por exemplo, Scheitle, 2009 e Marwell, 2004).

No início da década de 1990, a Itália enfrentou a maior crise da sua história enquanto república quando um grande escândalo de corrupção destruiu os partidos dominantes, o Partido da Democracia Cristã e o Partido Socialista, provocando amplas reivindicações de mudança no sistema político e institucional. Esta crise de legitimação, bem como a pressão geral para a localização e subsidiarização das políticas, criou uma oportunidade para que novos atores se apresentassem como sujeitos capazes de mudar o sistema político instalado. A reivindicação da autonomia das administrações locais face ao governo central partiu principalmente do partido Lega Nord, que começou a ganhar poder e influência nessa época devido à sua proposta de transformação da Itália num estado federal (Biorcio, 2003; Bellucci e Segatti, 2011). Simultaneamente, os mais importantes jornais italianos e líderes de opinião deram voz a insistentes reivindicações de empoderamento de atores da sociedade civil (associações sem fins lucrativos, empresários, professores e intelectuais sem ligações partidárias). 
Neste contexto, a Itália apresentava-se, assim, como o palco adequado para o CL. Tanto a tendência europeia para a localização e subsidiarização das políticas como a crise do sistema político italiano propiciaram uma grande janela de oportunidade política a novos atores capazes de assumir a liderança política e a agentes económicos capazes de fornecer serviços ao setor público. O CL desempenhou ambos os papéis ao mesmo tempo.

O movimento foi capaz de mobilizar a suas amplas e disciplinadas bases para apoiar os seus dirigentes nas eleições locais. Durante os anos do Movimento Popular e após a criação e desenvolvimento da CdO, o CL adquiriu crescente capacidade de influenciar um enorme número de pessoas nas comunidades locais, especialmente nas pequenas e médias cidades do norte de Itália, o que acabou por se revelar um instrumento excecional para construir consensos políticos à escala local.

Para além disso, a localização do poder político constitui o complemento perfeito da ideia firmemente enraizada na cultura do CL de que a construção do bem comum implica agir "aqui e agora”, em projetos locais, e não em projetos de larga escala e a longo prazo. Com esta ideologia simples e direta e uma eficaz liderança política, o CL exerceu forte influência sobre as políticas a nível local e conseguiu moldar algumas reformas institucionais. Através de uma ação concertada entre os seus dirigentes locais e regionais, por um lado, e as redes económicas locais e supralocais, por outro lado (Tosi e Vitale, 2011; Tajani, 2011), o CL conseguiu alcançar êxito tanto no campo político como no económico.

\subsection{O espaço político no contexto da Segunda República}

Uma outra janela de oportunidade política que se abriu para o CL na Lombardia foi propiciada pela transformação do sistema partidário italiano depois da crise de 1992-93. Em abril de 1993, quando o escândalo da corrupção já tinha destruído a popularidade dos partidos anteriormente dominantes, foi aprovada por referendo uma nova lei eleitoral baseada no sistema maioritário. O parlamento também aprovou o mesmo sistema para as eleições municipais, provinciais e regionais e a eleição direta de presidentes de câmara e outros dirigentes locais. Até então, e durante quase 50 anos, a Itália tinha sido uma espécie de democracia bloqueada, com dois grandes partidos mas sem verdadeira concorrência entre eles (Galli, 1984), baseado num sistema eleitoral proporcional, com coligações centristas no governo da nação e um grande partido comunista permanentemente na oposição. Após as reformas, o sistema partidário italiano polarizou-se entre duas coligações candidatas ao governo nacional: a coligação de centro-esquerda, composta maioritariamente por antigos comunistas e a ala de esquerda dos 
anteriores democratas cristãos, e a do centro-direita, constituída principalmente pela Forza Italia (o novo partido de Silvio Berlusconi), a Alleanza Nazionale (surgida do anterior partido neofascista Movimento Sociale Italiano e da ala conservadora dos democratas cristãos) e a Lega Nord. Em 1994, apenas dois meses após a sua criação, a Forza Italia tornou-se o maior partido do país e a coligação de centro-direita ganhou as eleições nacionais. A grande força do partido de Berlusconi ficou a dever-se acima de tudo à enorme popularidade do seu líder e ao seu império mediático, mas o partido em si carecia de organização e de líderes políticos a nível local.

Logo a seguir à "revolução" política de 1993-94, os dirigentes políticos do CL juntaram-se a um pequeno partido de antigos democratas cristãos, sem formar alianças e, portanto, com pouca força eleitoral. Mas de repente mudaram de ideias, e em 1995, dois meses depois das eleições regionais, o CL aliou-se à Forza Italia com o fim de apresentar a candidatura do seu líder Roberto Formigoni à presidência da Lombardia, como já foi referido. A coligação de centro-direita ganhou as eleições regionais em quase todas as regiões do norte e Formigoni assumiu o seu primeiro mandato na presidência da Lombardia.

Como vemos, portanto, o CL foi capaz de aproveitar uma oportunidade política rara: o partido de Berlusconi representava uma poderosa arma eleitoral mas não tinha quase nenhuma implantação política a nível local. Ao aderir à coligação, o CL podia facilmente suprir esta falha através dos seus militantes bem organizados e dos seus experientes líderes locais. Tinha, assim, a possibilidade de fazer com que as suas causas se tornassem numa prioridade da coligação. Durante este período, o movimento adquiriu um imenso poder político a nível local, conquistando a presidência da Lombardia e conseguindo ocupar praticamente todos os cargos de topo na administração e nos serviços públicos - hospitais, estruturas de apoio social e agências de financiamento do desenvolvimento industrial local (Pinotti, 2010). A partir destas posições, os membros do CL puderam exercer uma forte influência sobre o processo regional de definição de políticas e promover a subsidiarização de muitos serviços públicos. Puseram em prática um amplo programa de liberalização e externalização de serviços públicos através de um sistema de vouchers, principalmente nas áreas da saúde, da educação e do apoio social. Muitos destes processos de subsidiarização foram concebidos exatamente à medida das empresas da CdO espalhadas por toda a região (Bifulco et al., 2008; De Leonardis, 2011). Os membros do movimento assumiram também posições de destaque quer em grandes cidades como Milão (onde chefiam o gabinete de planeamento urbano há 14 anos), quer em cidades médias nas áreas mais importantes da região (Giorgi e Polizzi, 2011). 
A poderosa rede baseada na "amizade" e na "fé" revelou ser um eficaz meio de exercer influência política a partir do nível local para o nacional. A articulação entre estas duas arenas é claramente demonstrada pela experiência do Banco Alimentar e do Siticibo, um programa de recolha de alimentos excedentes de cantinas, hospitais e escolas para distribuição aos sem-abrigo. Até recentemente, esta era uma atividade proibida por motivos de higiene, mas, através da rede do CL, o que começou como uma proposta local transformou-se numa lei nacional. O poder adquirido pelo movimento ao nível nacional revela-se também no facto de que Angelino Alfano, o sucessor de Berlusconi no PDL, tem procurado angariar o apoio do CL para renovar a imagem política do partido, recuperar a sua credibilidade no meio católico depois dos escândalos sexuais em que Berlusconi esteve envolvido e reorganizar as causas e prioridades políticas do partido.

\subsection{O papel da Igreja Católica}

Se as dinâmicas específicas do cenário político italiano têm um papel fundamental na explicação do grande êxito do CL na Lombardia, não podemos esquecer um outro fator importante de promoção da ação deste movimento a nível político: o apoio do Papa e da Igreja Católica italiana.

A partir da década de 1970, nos últimos anos do pontificado de Paulo VI e durante o de João Paulo II, os novos movimentos católicos foram vivamente promovidos como um meio de revigorar uma igreja debilitada. ${ }^{11}$ O CL foi um dos que receberam o forte apoio do Vaticano, e a visita do Papa ao encontro anual do movimento em Rimini em 1982 foi simbólica dessa relação próxima.

No início da década de 1990, o Cardeal Camillo Ruini, presidente da Conferência Episcopal italiana, pessoalmente escolhido pelo Papa, começou a defender a necessidade de uma nova presença pública mais visível da Igreja Católica na esfera cultural. Como o partido católico que dominara a política italiana durante muitas décadas, o Partido da Democracia Cristã, estava a desaparecer, a Igreja procurou recuperar o seu papel central na sociedade através do chamado "Projeto Cultural", que envolveu o uso estratégico e sistemático de todos os meios ao seu dispor para propagar a voz da hierarquia na esfera pública e defender a identidade católica do Estado italiano. Entre os instrumentos usados pelo Cardeal Ruini, podemos mencionar o jornal diário nacional Avvenire, da Conferência Episcopal italiana,

\footnotetext{
${ }_{11}$ Entre os movimentos mais populares, podemos mencionar o Comunhão e Libertação, o Movimento dos Focolares, o Caminho Neocatecumenal, a Renovação Carismática Católica e, embora não seja oficialmente reconhecida como movimento, a Opus Dei (cf. Garelli, 2006 e Pace, 1988).
} 
e a prestigiada Universidade Católica em Milão, bem como a forte presença da Conferência Episcopal nos meios de comunicação social do país.

O CL era o candidato ideal para desempenhar o papel de arauto da identidade católica da nação, e esse aliás foi sempre um traço distintivo de movimento. As intervenções do CL nos debates públicos (nas universidades, nos jornais e nos debates políticos) manifestavam a preocupação constante de salientar as diferenças entre as visões cristãs e não cristãs da realidade. Os seus esforços para organizar um evento à escala nacional, o Encontro Anual de Rimini, tiveram por objetivo tornar a sua presença visível na sociedade italiana. Perseguindo a sua missão, o CL apoiou generosamente as campanhas políticas mais importantes da Igreja Católica, nomeadamente a campanha do direito à vida, realizada durante o referendo sobre o aborto em 1981, e a campanha contra a procriação medicamente assistida, que foi objeto de referendo em 2005. Ao mesmo tempo, nos últimos 15 anos, as hierarquias da Igreja Católica têm dado apoio frequente aos dirigentes políticos do CL nas eleições locais e nacionais. É também relevante mencionar que o Papa Bento XVI criou, em 2010, o Pontifício Conselho para a Promoção da Nova Evangelização, um órgão muito desejado por Giussani, tendo nomeado Angelo Scola (colaborador do CL) como seu membro e Julián Carrón (atual presidente do CL) como consultor, entre outros. Para além disto, em fevereiro de 2012 teve início o processo de beatificação de Luigi Giussani.

\section{Algumas conclusões}

Apesar de a nossa investigação se encontrar numa fase inicial, podemos estabelecer algumas conclusões com base na análise da estrutura de oportunidades políticas em que o CL tem operado.

Os estudos sociológicos sobre o CL têm-se centrado quer na sua ideologia política, quer no movimento religioso em si (frequentemente definido como fundamentalista ou integrista). Optámos por incluir uma outra perspetiva, analisando a estrutura de oportunidades políticas deste movimento.

Começámos por abordar a autorrepresentação do CL, incidindo especificamente na sua conceção do envolvimento político como parte do compromisso religioso. Nesse sentido, salientámos os aspetos fundamentais da identidade do CL com respeito ao movimento em si, bem como as representações das esferas social e política. A introdução de um foco específico sobre o sistema político permite que a análise apreenda mais das relações entre a religião e a política do que sobre o movimento em si. Por conseguinte, salientámos as relações íntimas entre as recentes mudanças no sistema político italiano e as razões para o êxito do CL na Lombardia, 
mostrando como, de facto, tem havido um processo de mútua adaptação e influência. A introdução de eleições diretas para a presidência das regiões e do princípio da subsidiariedade permitiram que o CL conquistasse um papel de maior destaque na esfera política da Lombardia. Por outro lado, estas oportunidades políticas levaram o CL a salientar a subsidiariedade como uma das suas marcas fundamentais. Na verdade, a referência a este princípio está praticamente ausente das primeiras análises da ideologia do CL, que incidem nas questões da liberdade de ensino e do envolvimento político.

O sucesso político de um movimento católico numa democracia ocidental é uma questão relevante para se entender a transformação do papel da religião na arena política. Podemos dizer que o papel crucial desempenhado pelos grupos religiosos na vida política não se restringe aos países islâmicos, tendo pelo contrário uma crescente influência em contextos ocidentais, como na Europa e nos Estados Unidos. Os movimentos cristãos podem assumir o papel de substitutos de movimentos políticos tradicionais em países onde os partidos clássicos perderam força e capacidade de mobilizar os cidadãos. Como muitos autores importantes têm salientado nos últimos anos (Crouch, 2004; Skocpol, 2003; Putnam, 2000; Stoker, 2006), a vida política nas democracias modernas é cada vez mais afetada pela reduzida participação das pessoas nos partidos políticos tradicionais. Os partidos de cartel (Katz e Mair, 1994) subsistem mais à custa dos recursos públicos e privados do que do trabalho diário dos seus militantes, e os seus programas são menos influenciados por ideologias do que pelos interesses dos grupos de pressão. Neste contexto, os grupos religiosos conseguem fomentar o envolvimento emocional e prático dos seus membros, dando-lhes motivações profundas e um forte sentido de solidariedade. Os recursos organizativos e os quadros ideológicos destes grupos têm a capacidade de revigorar o tipo de política de bases que as velhas formas de solidariedade já não são capazes de sustentar. Deste modo, o êxito do CL baseia-se numa mistura de ingredientes que muitos atores tradicionais, nomeadamente partidos, sindicatos e movimentos sociais, já não conseguem mobilizar: uma vida social vibrante ao nível local, uma conceção ideológica forte da sua missão no mundo, uma organização disciplinada e eficiente das suas atividades políticas e económicas e alianças fortes com atores religiosos, políticos e económicos ao nível supralocal.

A análise do CL na Lombardia, assim, aponta para alguns elementos importantes da investigação sobre movimentos religiosos na política. Para além disso, a análise da identidade do movimento e do sistema político permite compreender melhor a relação entre atores religiosos e políticos, bem como entre atores religiosos e sistema político. 
A trajetória do CL na Lombardia aponta também para o facto de que algo está a mudar na relação entre a política nacional e a local. OCL é um movimento com fortes raízes locais, mas capaz de fazer ouvir a sua voz na esfera política nacional. As mudanças do cenário político em Itália multiplicaram as arenas territoriais da política, redistribuindo poderes e competências nos diferentes níveis de governação. As cidades e as áreas urbanas de maior dimensão estão a transformar-se em espaços de atuação política por parte de atores coletivos privados com o fim de promover e defender os seus interesses (Brenner, 2004; Bagnasco e Le Galès, 2000; Sassen, 1991). Ser capaz de jogar em diferentes tabuleiros territoriais usando as esferas políticas local, regional e nacional para promover determinadas causas e atividades é um sinal muito significativo tanto da capacidade de adaptação às mudanças do sistema político como da capacidade de influenciar essas mudanças. O CL conseguiu ter uma ação política eficaz quando foi apoiado por atores nacionais, nomeadamente dirigentes políticos (Berlusconi), grupos económicos de âmbito nacional e internacional (CdO) e líderes religiosos (os bispos católicos italianos e o próprio Papa).

Em suma, na análise dos movimentos religiosos na política é crucial tomar em conta a forma como esses movimentos atuam num sistema político de múltiplos níveis. Como sugerimos relativamente ao $\mathrm{CL}$, as posições estratégicas relativamente à política variam consoante os diferentes níveis em causa. No âmbito nacional, o CL mantém relações com diferentes setores políticos, especialmente através do seu encontro anual, e dá apoio eleitoral à coligação de direita. No plano regional, na Lombardia, onde tem profundas raízes e uma densa rede, o movimento tem conseguido dominar o governo da região e influenciar a legislação. Mais, conseguiu estabelecer uma imensa rede de empresas e de atividades assistenciais. Nas regiões onde conta com um menor número de membros e de atividades, o CL também coopera com governos de diferentes cores políticas. Assim, a sua estratégia política varia de acordo quer com as condições políticas, quer com os âmbitos territoriais. É por esta razão que defendemos que deve fazer-se uma análise mais profunda das relações entre política e religião em diferentes níveis territoriais.

Tradução de

Teresa Tavares

\section{Referências bibliográficas}

Abbruzzese, Salvatore (1991), Comunione e liberazione: identità religiosa e disincanto laico. Roma-Bari: Laterza.

Abbruzzese, Salvatore (2001), Comunione e Liberazione. Dalle aule del liceo Berchet al Meeting di Rimini: storia e identità di un movimento. Bologna: Il Mulino. 
Almond, Gabriel A.; Appleby, R. Scott; Sivan, Emmanuel (2006), Religioni forti. L'avanzata dei fondamentalismi sulla scena mondiale. Bologna: Il Mulino. [publicado originalmente em inglês: Strong Religion: The Rise of Fundamentalisms Around the World. Chicago: University of Chicago Press, 2003].

Bagnasco, Arnaldo; Le Galès, Patrick (orgs.) (2000), Cities in Contemporary Europe. Cambridge: Cambridge University Press.

Bellucci, Paolo; Segatti, Paolo (orgs.) (2011), Votare in Italia: 1968-2008. Dall'appartenenza alla scelta. Bologna: Il Mulino.

Bianchi, Sandro; Turchini, Angelo (orgs.) (1975), Gli estremisti di centro. Il neo-integralismo cattolico degli anni'70: Comunione e Liberazione. Rimini-Firenze: Guaraldi.

Bifulco, Lavinia; Bricocoli, Massimo; Monteleone, Raffaele (2008), "Activation and Local Welfare in Italy. Trends, Issues, and a Case Study", Social Policy and Administration, 2, 143-159.

Biorcio, Roberto (2003), “The Lega Nord and the Italian Media System”, in Gianpietro Mazzoleni, Julianne Stewart e Bruce Horsfield (orgs.), The Media and Neo-populism. A Contemporary Comparative Analysis. Westport: Praeger, 71-94.

Bova, Vincenzo (2005), "Un carisma e i suoi seguaci: il cammino di Comunione e Liberazione", Religioni e società, 52, 105-114.

Brenner, Neil (2004), "Urban Governance and the Production of New State Spaces in Western Europe, 1960-2000”, Review of International Political Economy, 11(3), 447-488.

Camisasca, Massimo (2001), Comunione e Liberazione - Le origini (1954-1968). Milano: San Paolo.

Camisasca, Massimo (2003), Comunione e Liberazione - La ripresa (1969-1976). Milano: San Paolo.

Camisasca, Massimo (2006), Comunione e Liberazione - Il riconoscimento (1976-1984). Milano: San Paolo.

Cavallaro, Renato (1976), “Communion et manipulation”, Social Compass, 23(2-3), 259-262.

Centro Operaio (1975), Comunione e Liberazione. Una nuova "politica cattolica". Roma: Coines Edizioni.

Crouch, Colin (2004), Post-Democracy. Cambridge: Polity Press.

De Alessandri, Enrico (2010), Comunione e Liberazione: Assalto al potere in Lombardia. Lecce: BePress.

De Leonardis, Ota (2011), "Combining or Dividing Citizens. The Politics of Active Citizenship in Italy”, in Janet Newman e Evelien Tonkens (orgs.), Participation, Responsibility and Choice. Summoning the Active Citizen in Western European Welfare States. Amsterdam: Amsterdam University Press, 127-146.

Favale, Agostino (org.) (1991), Movimenti ecclesiali contemporanei. Dimensioni storiche, teologico-spirituali e apostoliche. Roma: LAS. 
Ferrera, Maurizio (2005), The Boundaries of Welfare: European Integration and the New Spatial Politics of Social Protection. Oxford-New York: Oxford University Press. Formigoni, Guido; Vecchio, Giorgio (1989), L'Azione cattolica nella Milano del Novecento. Milano: Rusconi.

Galli, Giorgio (1984), Il bipartitismo imperfetto: comunisti e democristiani in Italia. Milano: Mondadori.

Garelli, Franco (2006), "I nuovi movimenti, visibili e invisibili”, Il Mulino, 6, 1075-1085.

Gervasi, Francesco (2007), "Percorsi di ri-conversione al cattolicesimo: il caso di Comunione e Liberazione”, Religioni e società, 58, 97-108.

Giorgi, Alberta; Polizzi, Emanuele (2011), "La dimensione politica del governo locale", in Tommaso Vitale e Simone Tosi (orgs.), Piccolo Nord: scelte pubbliche e interessi privati. Milano: Bruno Mondadori, 177-201.

Guasco, Maurilio (1997), Storia del clero in Italia dall'Ottocento ad oggi. Roma-Bari: Laterza.

Guolo, Renzo; Pace, Enzo (1998), I fondamentalismi. Roma-Bari: Laterza.

Katz, Richard S.; Mair, Peter (1994), How Parties Organize. London: Sage.

Kazepov, Yuri (org.) (2010), Rescaling Social Policies: Towards Multilevel Governance in Europe. European Centre Vienna. Farnham, UK: Ashgate.

Marzano, Marco (1995), "Movimenti religiosi e azione politica: un confronto tra l'Azione Cattolica e Comunione Liberazione”, Quaderni di Scienza Politica, II(3), 371-436.

Marzano, Marco (1997), Il cattolico e il suo doppio. Organizzazioni religiose e Democrazia Cristiana nell'Italia del dopoguerra. Milano: Franco Angeli.

Marwell, Nicole P. (2004), "Privatizing the Welfare State: Nonprofit Community-Based Organizations as Political Actors”, American Sociological Review, 69, 265-291.

Ottaviano, Franco (1986), Gli estremisti bianchi. Comunione e liberazione, un partito nel partito, una chiesa nella chiesa. Roma: Datanews.

Pace, Enzo (1988), “Typologie des groupes religieux”, in Charles Baladier (org.), Le grand Atlas des religions. Paris: Encyclopaedia Universalis.

Pace, Enzo (1998), Il regime della verità. Mappa ed evoluzione dei fondamentalismi religiosi contemporanei. Bologna: Il Mulino.

Pinotti, Ferruccio (2010), La lobby di Dio. Fede, affari e politica. La prima inchiesta su Comunione e Liberazione e la Compagnia delle Opere. Milano: ChiareLettere.

Putnam, Robert (2000), Bowling Alone. The Collapse and Revival of American Community. New York: Simon and Schuster.

Riccardi, Andrea (2007), Il partito romano: politica italiana, Chiesa cattolica e Curia romana da Pio XII a Paolo VI. Brescia: Morcelliana.

Ronza, Robi (1976), Comunione e Liberazione. Interviste a Luigi Giussani. Milano: Jaca book.

Saraceno, Chiara; Rusconi, Gian Enrico (1970), Ideologia religiosa e conflitto sociale. Bari: De Donato. 
Sassen, Saskia (1991), The Global City. Princeton: Princeton University Press.

Scheitle, Cristopher P. (2009), "Identity and Government Funding in Christian Nonprofits”, Social Science Quarterly, 90(4), 816-833.

Skocpol, Theda (2003), Diminished Democracy: From Membership to Management in American Civic Life. Norman: University of Oklahoma Press.

Stoker, Gerry (2006), Why Politics Matters: Making Democracy Work. Basingstoke: Palgrave Macmillan.

Tajani, Cristina (2011), "Il governo economico del territorio", in Simone Tosi e Tommaso Vitale (orgs.), Piccolo Nord: scelte pubbliche e interessi privati. Milano: Bruno Mondadori, 123-147.

Tilly, Charles; Tarrow, Sidney (2007), Contentious Politics. Boulder: Paradigm Publishers.

Tosi, Simone; Vitale, Tommaso (orgs.) (2011), Piccolo Nord: scelte pubbliche e interessi privati. Milano: Bruno Mondadori.

Zadra, Dario (1994), "Comunione e Liberazione: A Fundamentalist Idea of Power”, in Martin Marty e R. Scott Appleby (orgs.), Accounting for Fundamentalism. Chicago: University of Chicago Press, 124-148. 